\title{
Comparison of Short Segment Pedicle Screw Fixation Including the Fractured Vertebra Versus Long Segment Fixation in Thoracolumbar Fractures
}

\author{
Engin Çetin¹ (1D, Ali Öner2 (1) \\ ${ }^{1}$ University of Health Sciences Turkey, Gaziosmanpaşa Training and Research Hospital, Clinic of Orthopedics and Traumatology, İstanbul, \\ Turkey \\ ${ }^{2}$ Metin Sabancı Baltalimanı Bone Diseases Training and Research Hospital, Clinic of Orthopedics and Traumatology, İstanbul, Turkey
}

Cite this article as: Çetin E, Öner A. Comparison of Short Segment Pedicle Screw Fixation Including the Fractured Vertebra Versus Long Segment Fixation in Thoracolumbar Fractures. JAREM 2020;10(1): 32-5

\begin{abstract}
Objective: To compare the radiologic outcomes of short-segment fixation (SSF-P) with screw insertion into the fractured vertebra versus long-segment fixation (LSF), without fractured-level screw for the treatment of unstable thoracolumbar fractures.

Methods: Radiological parameters of 17 patients who had SSF-P or LSF for the treatment of unstable thoracolumbar fractures and had at least oneyear fallow-up duration were retrospectively evaluated. Local kyphosis (LK) angle and anterior vertebral height (AVH) value were measured from the preoperative, early postoperative and follow-up radiographs; intergroup comparisons were performed.

Results: The mean age of the patients (male: 12 , female: 5 ) was $50.1 \pm 12.8$ years and the mean follow-up duration was $15.7 \pm 6.4$ months. Fracture levels were L1 $(n=8), L 2(n=5), T 12(n=2), L 3(n=1)$ and L4 ( $n=1)$. SSF-P was performed for 9 patients and LSF for 8 patients. The mean preoperative LK angles were $17.4 \pm 10.6^{\circ}$ in the SSF-P group and $16.5 \pm 5.8^{\circ}$ in the LSF group ( $p=0.83$ ). In early postoperative measurements, the mean LK angles were $6.9 \pm 5.6^{\circ}$ in the SSF-P group and $10.3 \pm 7.3^{\circ}$ in the LSF group $(p=0.14)$. In the follow-up evaluation, they were $8.8 \pm 5.8^{\circ}$ and $12.0 \pm 7.2^{\circ}$, respectively $(p=0.36)$. Preoperative mean AVH values were $72.4 \pm 14.5 \%$ in the SSF-P group and $56.4 \pm 14.8 \%$ in the LSF group ( $p=0.05)$. In early postoperative measurements, AVH values were $88.5 \pm 9.5 \%$ in the SSF-P group and $75.6 \pm 18.5 \%$ in the LSF group ( $p=0.13$ ). In the follow-up evaluation, they were $86.6 \pm 11.3 \%$ and $69.1 \pm 19.5 \%$, respectively $(p=0.06)$.
\end{abstract}

Conclusion: Radiological outcomes of SSF-P were similar to LSF in the treatment of unstable thoracolumbar burst fractures. We recommend the SSF-P method, which provides a stable fixation without sacrificing mobile segments, in the treatment of unstable burst fractures.

Keywords: Thoracolumbar fracture, instrumentation, pedicle screw, trauma

\section{INTRODUCTION}

Posterior instrumentation with pedicle screws is the most commonly used method in the treatment of unstable thoracolumbar fractures. It is possible to detect all three columns of the spine and correct the deformity caused by the fracture without experiencing potential complications of anterior surgery (1). With the short segment posterior pedicle screw fixation short-segment fixation (SSF), it is aimed to protect the movable segments by placing screws on the upper and lower level of the fracture line. However, with this method, high rates of failure and related progressive kyphosis have been reported in many studies $(2,3)$. While it is possible to provide a more stable fixation with long segment posterior pedicle screw fixation (LSF), movable segments are sacrificed (3).

In order to increase the stability of SSF, placing screws on pedicles in the broken spine is a method recommended in biomechanical

ORCID IDs of the authors: E.Ç. 0000-0002-0367-0822; A.Ö. 0000-0002-0438-8335. 
standard deviation. The Student's t-test was used for statistical analysis. The degree of significance was determined as $p<0.05$.

\section{RESULTS}

Of the 17 patients, 12 were male and 5 were female. Their mean age was $50.1 \pm 12.8$ years and mean follow-up time was $15.7 \pm 6.4$ months. Nine patients had concomitant extremity, pelvis, and/or rib fractures. The fracture level was L1 in 8 patients, L2 in 5 patients, T12 in 2 patients, and L3 in one patient, and L4 in one patient. According to the AOSpine thoracolumbar fracture classification, 9 cases were evaluated as type A4, 8 cases were evaluated as type B2. According to the load sharing classification, while the mean score of all patients was $6.2 \pm 1.0$, it was $5.5 \pm 0.5$ in the SSF-P group and $6.0 \pm 1$ in the LSF group ( $p=0.11$ ). SSF-P was applied to 9 patients and LSF was applied to 8 patients (Table 1) (Figure 2, 3).

While the mean LK angle value before surgery was $17.4 \pm 10.6$ degrees in the SSF-P group, it was $16.5 \pm 5.8$ degrees in the LSF group ( $p=0.83$ ). AVH value was measured as $72.4 \pm 14.5 \%$ in the SSF-P group and $56.4 \pm 14.8 \%$ in the LSF group $(p=0.05)$. In the early postoperative period, the mean LK angle value was $6.9 \pm 5.6$ degrees in the SSF-P group and $10.3 \pm 7.3$ degrees in the LSF group. Decreased LK angle values observed in the postoperative period were statistically significant for both groups $(p=0.003$ and $p=0.001$ ). Significant improvements in $\mathrm{AVH}$ values were also observed. The mean value was $88.5 \pm 9.5 \%$ in the SSF-P group and $75.6 \pm 18.5 \%$ in the LSF group ( $p=0.01$ and $p=0.03$ ). When the LK angle and AVH values between the SSF-P and LSF groups were compared in the early postoperative period, the differences were computed tomography and magnetic resonance imaging before surgery were evaluated according to the AOSpine thoracolumbar fracture classification and load sharing classification $(9,10)$.

Local kyphosis (LK) angle (wedge angle) and anterior vertebral height $(\mathrm{AVH})$ values were measured by two independent surgeons on preoperative, early postoperative and final followup radiographs. LK angle is the Cobb angle value between the upper and lower surfaces of the broken vertebra in lateral X-ray. For the AVH, the anterior wall height of the broken vertebra was measured; this value was divided by the anterior height average of the adjacent vertebrae at an upper and lower level (6). The obtained value was recorded in percentage (Figure 1). Screw breakage, loosening and rod breakage were evaluated as implant failure.

Surgical technique: All patients in the study were applied posterior midline approach in prone position under general anesthesia. After checking the level of fracture under scopy, monoaxial and/or polyaxial pedicle screws were placed bilaterally. Fracture reduction was achieved with compression and distraction forces and using appropriate contoured rods. Local bone material was used for fusion.

\section{Statistical Analysis}

Microsoft Excel for Mac 2011 program was used for statistical evaluations. Preoperative, postoperative and follow-up values obtained by radiological measurements were given as mean \pm

\begin{tabular}{|l|l|l|l|l|l|l|}
\hline \multicolumn{2}{|c|}{$\begin{array}{l}\text { Table 1. } \\
\text { features }\end{array}$} & Details of patients' & \multicolumn{3}{l|l}{ demographic and fracture } \\
\hline & Age & Gender & $\begin{array}{l}\text { Fracture } \\
\text { level }\end{array}$ & AOSpine & $\begin{array}{l}\text { Load } \\
\text { sharing }\end{array}$ & $\begin{array}{l}\text { Type of } \\
\text { fixation }\end{array}$ \\
\hline 1 & 56 & M & L3 & A4 & 5 & SSF-P \\
\hline 2 & 37 & M & L2 & B2 & 7 & SSF-P \\
\hline 3 & 61 & F & L2 & A4 & 6 & SSF-P \\
\hline 4 & 50 & M & L1 & A4 & 6 & SSF-P \\
\hline 5 & 29 & M & L4 & A4 & 6 & SSF-P \\
\hline 6 & 51 & M & L2 & B2 & 4 & SSF-P \\
\hline 7 & 34 & M & L1 & B2 & 5 & SSF-P \\
\hline 8 & 23 & M & L1 & A4 & 7 & SSF-P \\
\hline 9 & 59 & M & L1 & A4 & 6 & SSF-P \\
\hline 10 & 38 & M & L2 & B2 & 7 & LSF \\
\hline 11 & 67 & F & L1 & B2 & 7 & LSF \\
\hline 12 & 61 & M & L2 & A4 & 7 & LSF \\
\hline 13 & 61 & F & L1 & B2 & 7 & LSF \\
\hline 14 & 58 & F & L1 & A4 & 7 & LSF \\
\hline 15 & 51 & M & T12 & B2 & 8 & LSF \\
\hline 16 & 50 & F & T12 & B2 & 5 & LSF \\
\hline 17 & 65 & M & L1 & A4 & 5 & LSF \\
\hline M: Male, F: female, SSF: short-segment fixation, LSF: fractured-level screw
\end{tabular}




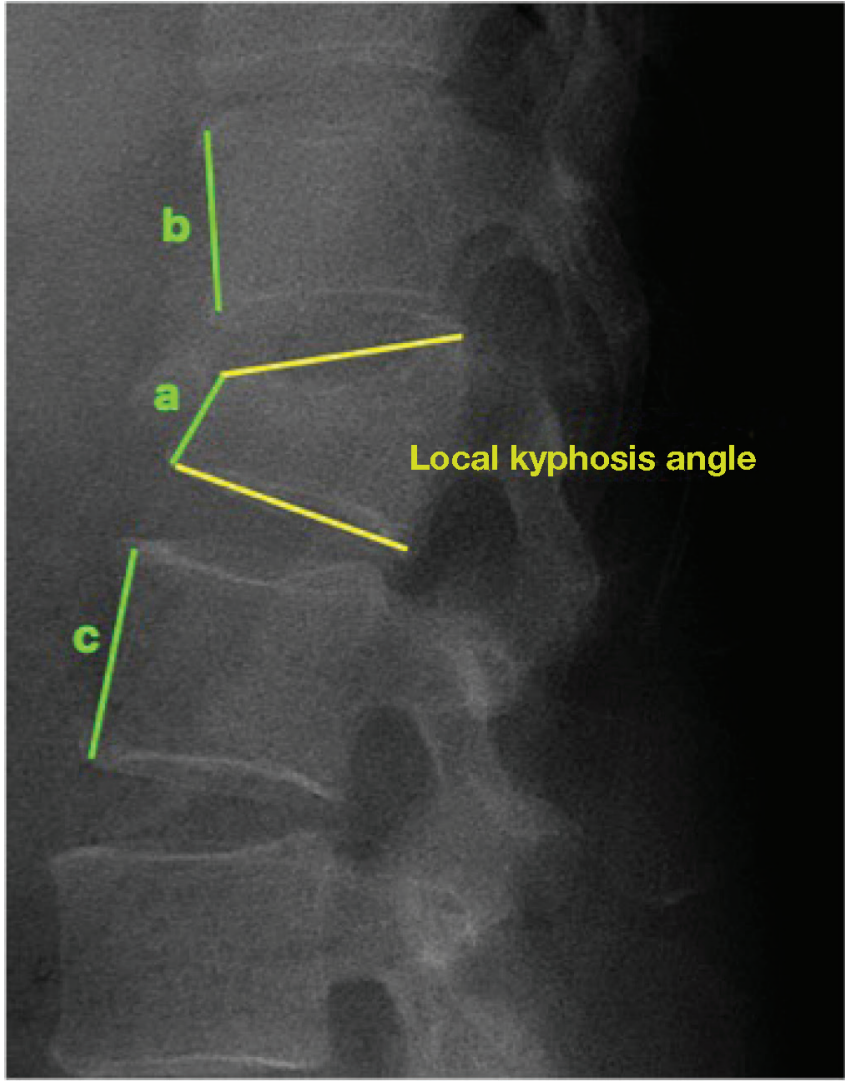

Figure 1. Values measured on the lateral graph a: Local kyphosis angle: Cobb angle between the upper and lower surfaces of the broken vertebra b: Anterior vertebral height (\%): $a /[(b+c) / 2] \times 100$

not statistically significant $(p=0.14$ and $p=0.13$ ) (Table 2 ).

The LK angle values measured in the last follow-up graphs of the patients were $8.8 \pm 5.8$ degrees in the SSF-P group and $12.0 \pm 7.2$ degrees in the LSF group. These increases observed according to the early postoperative values were found statistically significant $(p=0.006$ and $p=0.001)$. In follow-up radiographs, AVH value was measured as $86.6 \pm 11.3 \%$ in the SSF-P group and $69.1 \pm 19.5 \%$ in the LSF group. Changes in these values were not significant for both groups compared to the early postoperative period ( $p=0.05$ and $p=0.09$ ). When the LK angle and $\mathrm{AVH}$ values measured in the last follow-up graphs in the SSF-P and LSF groups were compared, the differences were not statistically significant $(p=0.36$ and $p=0.06$ ) (Table 2).

Neurological complications and implant failure did not develop in any patient in the postoperative period. One patient had superficial infection, which was treated with local wound care and antibiotics, and one patient had a resistant infection that required removal of the implants in the late period.

\section{DISCUSSION}

Our study reveals that in unstable thoracolumbar burst fractures, the radiological results of SSF and LSF applied with the insertion of screws to the pedicles at the broken level are not different in the early postoperative and mid-term follow-up.
Table 2. Comparison of radiological data between groups

\begin{tabular}{|l|l|l|l|}
\hline & SSF-P & LSF & $\mathbf{p}$ \\
\hline Local kyphosis angle $\left(^{\circ}\right)$ & & & \\
\hline \begin{tabular}{l} 
Preop \\
\hline Postop
\end{tabular} & $17.4 \pm 10.6$ & $16.5 \pm 5.8$ & 0.83 \\
\hline Follow-up & $6.9 \pm 5.6$ & $10.3 \pm 7.3$ & 0.14 \\
\hline Anterior vertebra height (\%) & $8.8 \pm 5.8$ & $12.0 \pm 7.2$ & 0.36 \\
\hline Preop & $72.4 \pm 14.5$ & $56.4 \pm 14.8$ & 0.05 \\
\hline Postop & $88.5 \pm 9.5$ & $75.6 \pm 18.5$ & 0.13 \\
\hline Follow-up & $86.6 \pm 11.3$ & $69.1 \pm 19.5$ & 0.06 \\
\hline SSF: Short-segment fixation, LSF: fractured-level screw & \\
\hline
\end{tabular}

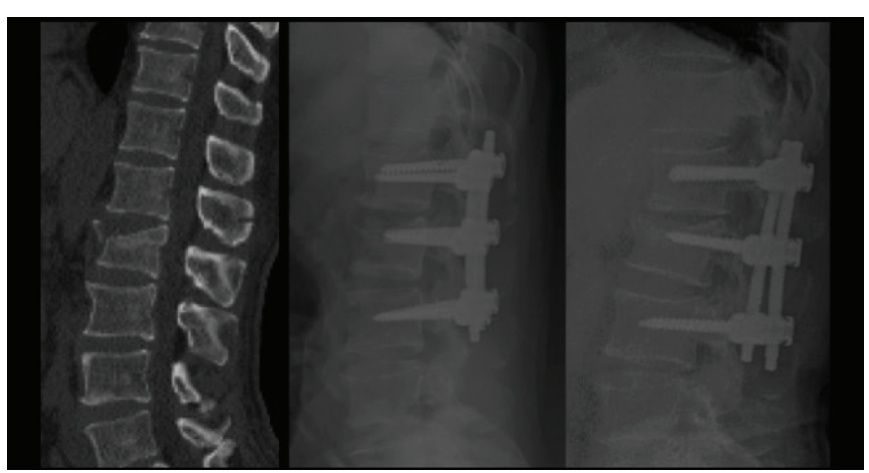

Figure 2. Preop, early postoperative and $12^{\text {th }}$ month follow-up images of a 51-year-old male patient with an L2 burst fracture (AOSpine type B2, load sharing score 4)

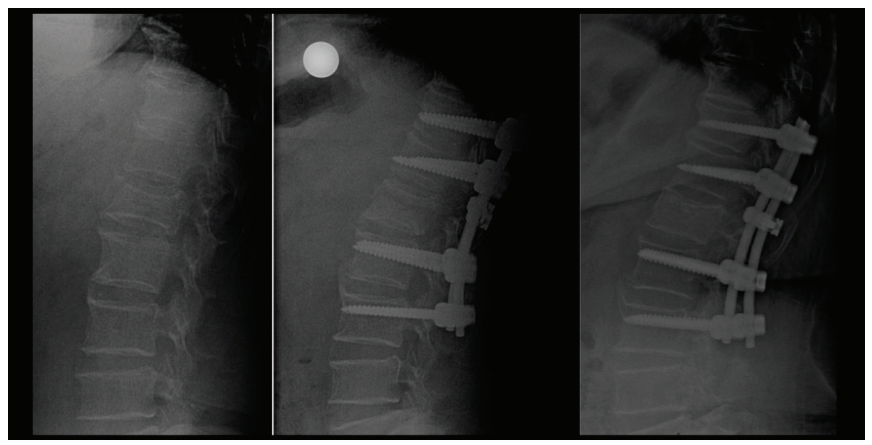

Figure 3. Preop, early postoperative and $18^{\text {th }}$ month follow-up images of a 58-year-old woman with L1 burst fracture (AOSpine type A4, load sharing score 7)

Our results are compatible with similar studies in the literature. In the study of Pellise et al. (6), evaluating the radiological results of 72 patients, they reported that 6-screw fixation was sufficient for the treatment of burst fractures of the thoracolumbar region. In patients with load bearing scores $\geq 7$, they detected an increase in LK angle less than $5^{\circ}$ in the first 6 months. In our study, LK angle values in both the SSF-P and LSF groups increased by 1.9 and 1.7 degrees, respectively, compared to the early postoperative period in the last follow-up graphs. This increase was found statistically significant. Changes in AVH values were not found significant. However, there was no significant difference in the follow-up LK angle values of both groups with similar load bearing scores. 
Peer-review: Externally peer-reviewed.

Author Contributions: Concept - E.Ç.; Design - E.Ç., A.Ö.; Supervision - E.Ç.; Data Collection and/or Processing - E.Ç., A.Ö.; Analysis and/ or Interpretation - E.Ç., A.Ö.; Literature Search - E.Ç.; Writing Manuscript E.Ç.; Critical Review - E.Ç.

Conflict of Interest: The authors have no conflict of interest to declare.

Financial Disclosure: The authors declared that this study has received no financial support.

\section{REFERENCES}

1. McLain RF. The biomechanics of long versus short fixation for thoracolumbar spine fractures. Spine (Phila Pa 1976) 2006; 31: 70-9.

2. McLain RF, Sparling E, Benson DR. Early failure of short-segment pedicle instrumentation for thoracolumbar fractures. A preliminary report. J Bone Joint Surg Am 1993; 75: 162-7.

3. McDonnell M, Shah KN, Paller DJ, Thakur NA, Koruprolu S, Palumbo MA, et al. Biomechanical Analysis of Pedicle Screw Fixation for Thoracolumbar Burst Fractures. Orthopedics 2016; 39: 514-8.

4. Mahar A, Kim C, Wedemeyer M, Mitsunaga L, Odell T, Johnson B, et al. Short-segment fixation of lumbar burst fractures using pedicle fixation at the level of the fracture. Spine (Phila Pa 1976) 2007; 32: 1503-7.

5. Norton RP, Milne EL, Kaimrajh DN, Eismont FJ, Latta LL, Williams SK. Biomechanical analysis of four- Versus six-screw constructs for short-segment pedicle screw and rod instrumentation of unstable thoracolumbar fractures. Spine J 2014; 14: 1734-9.

6. Pellisé F, Barastegui D, Hernandez-Fernandez A, Barrera-Ochoa S, Bagó $J$, Issa-Benítez D, et al. Viability and long-term survival of short-segment posterior fixation in thoracolumbar burst fractures. Spine J 2015; 15 : 1796-803.

7. Kanna RM, Shetty AP, Rajasekaran S. Posterior fixation including the fractured vertebra for severe unstable thoracolumbar fractures. Spine J 2015; 15: 256-64.

8. Cheng LM, Wang JJ, Zeng ZL, et al. Pedicle screw fixation for traumatic fractures of the thoracic and lumbar spine. Cochrane Database Syst Rev. 2013; 31:CD009073

9. Vaccaro AR, Oner C, Kepler CK, Dvorak M, Schnake K, Bellabarba C, et al. AOSpine Thoracolumbar Spine Injury Classification System. Spine (Phila Pa 1976) 2013; 38: 2028-37.

10. McCormack T, Karaikovic E, Gaines RW. The load sharing classification of spine fractures. Spine (Phila Pa 1976) 1994; 19: 1741-4.

11. Farrokhi MR, Razmkon A, Maghami Z, Nikoo Z. Inclusion of the fracture level in short segment fixation of thoracolumbar fractures. Eur Spine J. 2010; 19: 1651-6.

12. Guven O, Kocaoglu B, Bezer M, Aydin N, Nalbantoglu U. The use of screw at the fracture level in the treatment of thoracolumbar burst fractures. J Spinal Disord Tech 2009; 22: 417-21.

13. Dobran M, Nasi D, Brunozzi D, di Somma L, Gladi M, lacoangeli M, et al. Treatment of unstable thoracolumbar junction fractures: short-segment pedicle fixation with inclusion of the fracture level versus long-segment instrumentation. Acta Neurochir (Wien) 2016; 158: 1883-9.
Ethics Committee Approval: Ethics committee approval was received for this study from the Ethics Committee of the Clinical Researches of University of Health Sciences Turkey, Gaziosmanpaşa Training and Research Hospital (approval number: 121, date: 16.01.2019).

Informed Consent: This is a retrospective study. 